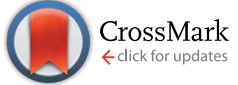

Cite this: RSC Adv., 2016, 6, 110535

Received 1st October 2016

Accepted 7th November 2016

DOI: 10.1039/c6ra24450e

www.rsc.org/advances

\section{Sciatic nerve regeneration induced by glycosaminoglycan and laminin mimetic peptide nanofiber gels $\dagger$}

\author{
Busra Mammadov, t $^{\mathrm{a}}$ Melike Sever, ta $^{\mathrm{a}}$ Mevhibe Gecer, ${ }^{a}$ Fatih Zor, ${ }^{\mathrm{b}}$ Sinan Ozturk, ${ }^{\mathrm{c}}$

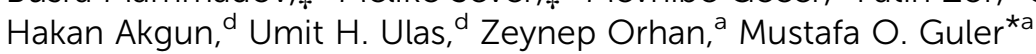 \\ and Ayse B. Tekinay ${ }^{\star a}$
}

In the USA, 20 million patients suffer from neuropathy caused by peripheral nerve injuries, which costs approximately $\$ 150$ billion annually. For longer nerve gaps and multiple injury sites, it is essential to use nerve guidance conduits for healthy pathfinding of regenerating axons. Here, extracellular matrix mimetic peptide nanofiber hydrogels were used for functionalizing guidance conduits to enhance neuronal regeneration in the distal stump of full transaction sciatic nerve injury in rats with functional repair. Conduits filled with heparan sulfate and laminin mimetic peptide nanofibers significantly improved electromyography response and promoted neuronal regeneration in a rat model of sciatic nerve defect. In addition, Schwann cells cultured on these nanofibers showed increased viability and significantly enhanced nerve growth factor (NGF) release. Overall, these results suggest that extracellular matrix mimetic peptide nanofibers present a promising treatment option for peripheral nerve injuries.

\section{Introduction}

High incidences of peripheral nerve injury (PNI) result in significant functional disability to the patients and economic burden due to healthcare costs. Approximately $1 \times 10^{5}$ patients are diagnosed with peripheral nerve injuries per year in the US and Europe, and 20 million patients are known to suffer from peripheral neuropathy in the US., ${ }^{1,2}$ Several materials and techniques have been used to enhance nerve regeneration across a nerve gap. However, the functional outcomes following these techniques are not ideal. ${ }^{3}$ Current therapies have low success rates, leading to less than half of the patients fully recovering with sufficient motor and sensory function. ${ }^{1}$ Depending on the length of the nerve gap formed by the injury, different therapeutic approaches can be considered: coaptation can only be used for very short lesions under $4 \mathrm{~mm}$, and autografting is considered as the clinical gold standard for treatment of injuries with larger gap distance. ${ }^{4}$ In autografting, a nerve

${ }^{a}$ Institute of Materials Science and Nanotechnology, National Nanotechnology Research Center (UNAM), Bilkent University, Ankara 06800, Turkey. E-mail: moguler@unam.bilkent.edu.tr; atekinay@bilkent.edu.tr

${ }^{b}$ Department of Plastic and Reconstructive Surgery, Gülhane Military Medical Academy, Ankara 06010, Turkey

${ }^{\circ}$ Department of Plastic and Reconstructive Surgery, Gülhane Military Medical Academy, Haydarpasa Training Hospital, Istanbul, 34668, Turkey

${ }^{d}$ Department of Neurology, Gülhane Military Medical Academy, Ankara 06010, Turkey $\dagger$ Electronic supplementary information (ESI) available. See DOI: 10.1039/c6ra24450e

\$ B. Mammadov and M. Sever contributed equally to this work. segment harvested from another site of the body, preferably from a region where nerve loss can be tolerated, is used to bridge the nerve ends at the site of injury. Peripheral nerves have endogenous regenerative potential; however, lack of guidance molecules can make the process chaotic. Hence, guidance cues are essential for pain-free regeneration of the peripheral nerve through the end target organ. ${ }^{5}$ Transplanted nerve section in the autograft provides these guidance cues, including endoneural tubes as well as Schwann cells. However, application of this technique is limited by the length of the nerve section required. Harvesting long nerve segments to treat very long gap distances or multiple injury sites is not possible. Moreover, harvesting autograft causes donor site morbidity and lengthens the operation time. An alternative to autograft is nerve guidance conduits (NGCs), which are hollow tubes used to bridge transected nerve stumps for enhancing axonal regeneration. They can be synthesized at any length and size, relieving the gap distance limit in regeneration after PNI. NGCs provide a barrier against scar tissue infiltration and allow axonal elongation through the distal stump. Improving functional outcomes of NGCs with multiple neuroinductive signals can better mimic the permissive environment of the peripheral nervous system (PNS), and mimicking signals produced in periaxonal space by Schwann cells is quite helpful for enhancing regeneration. ${ }^{6}$

Here, we used self-assembling peptide nanofiber gels containing neuroinductive signals for biofunctionalization of clinically used polymeric NGCs. These gels are made of nanofibers containing laminin derived and heparan sulfate 
mimicking peptide sequences and are used to fill the interior lumen of the NGC. Laminin is an extracellular matrix (ECM) protein abundantly present in basal lamina of peripheral nerves which is secreted by Schwann cells. ${ }^{7}$ Basal lamina production is upregulated upon PNI and it has a significant role in the regenerative potential of the PNS. ${ }^{8}$ Besides its role as a positive regulator of neurite outgrowth, laminin is also important in Schwann cell differentiation after injury and its ablation impairs axon regeneration severely. ${ }^{9}$ Heparan sulfate proteoglycans (HSPGs) are also PNS basal lamina components. ${ }^{10}$ Heparan sulfate (HS) is known to bind to growth factors as well as cell surface receptors. Binding of HS increases the local concentration of growth factors, and improves their stability, enhancing their receptor binding. ${ }^{11,12}$ Depletion of the basal lamina in large gap injuries leads to loss of guidance molecules including laminin and growth factors and it is a limiting factor in axonal regeneration. Overcoming this limitation can be possible by mimicking basal lamina through use of synthetic nanofibers. Short peptide sequences presented on these nanofibers can bind to cell surface receptors and growth factors to induce axonal regeneration. Besides this, the scaffolds presenting laminin derived signal were previously found to induce cerebellar Purkinje cell development ${ }^{13}$ and selective differentiation of neural progenitor cells. ${ }^{14}$ Also, the scaffolds bearing both laminin derived signals and HS mimicking moieties were previously found to improve neurite outgrowth in vitro. ${ }^{15}$ Here, biofunctionalization of a polymeric hollow nerve guidance conduit was carried out with a synthetic peptide nanofiber system that can mimic the activity of both laminin and heparan sulfate proteoglycans. The suitable mechanical and physical guidance cues of these bioactive peptide nanofibers enhanced neural regeneration after complete transection of sciatic nerve. Behavioral, electromyographic and histological analyses revealed that peptide nanofiber biofunctionalized NGCs present a promising therapeutic potential for the treatment of PNI.

\section{Materials and methods}

\subsection{Materials}

9-Fluorenylmethoxycarbonyl- (Fmoc) and tert-butoxycarbonyl (Boc)-protected amino acids, [4-[ $\alpha-\left(2^{\prime}, 4^{\prime}\right.$-dimethoxyphenyl $)$ Fmoc-aminomethyl]enoxy]acetamidonorleucyl-MBHA resin (Rink amide MBHA resin), Fmoc-Asp(OtBu)-Wang resin and 2(1H-benzotriazol-1-yl)-1,1,3,3-tetramethyluronium hexafluorophosphate (HBTU) were purchased from NovaBiochem and ABCR. The other chemicals were purchased from Thermo Fisher Scientific, USA, Merck Millipore, USA, or Sigma-Aldrich, USA. Neurolac TW nerve guidance conduits (NG02-015/03) were obtained from Polyganics, The Netherlands and used as directed. Live/Dead Assay (L3224) was purchased from Thermo Fisher Scientific, USA. Antibodies and reagents for ELISA assay and poly-L-lysine were purchased from R\&D Systems, USA. DMEM-D-valine was purchased from Pan-Biotech, Germany. All other materials used in this study were purchased from Thermo Fisher Scientific, USA, and/or Sigma-Aldrich, USA.

\subsection{Synthesis and purification of peptide amphiphiles}

Peptide amphiphiles (PAs) were synthesized on Rink Amide MBHA resin or Fmoc-Glu(OtBu)-Wang resin by the Fmoc solid phase peptide synthesis method. Amino acid couplings were performed with 2 equivalents of Fmoc-protected amino acid, 1.95 equivalents HBTU and 3 equivalents of $N, N$-diisopropylethylamine (DIEA) for $3 \mathrm{~h}$. Fmoc removal was performed with $20 \%$ piperidine/dimethylformamide solution (DMF) for $20 \mathrm{~min}$. Acetic anhydride solution (10\%) in DMF was used to block remaining free amine groups after amino acid coupling. After each step, resin was washed 3 times with DMF, 3 times with dichloromethane (DCM) and 3 times with DMF, respectively. Sulfobenzoic acid was added to the side chain of lysine to synthesize sulfonated GAG-PA. A lysine residue with 4-methyltrityl (Mtt) side chain protection was used for selective deprotection of amine groups in GAG-PA. Mtt removal was performed by shaking resin for $5 \mathrm{~min}$ with TFA: triisopropylsilane (TIS) $: \mathrm{H}_{2} \mathrm{O}:$ DCM in the ratio of $5: 2.5: 2.5: 90$. Cleavage of the PAs from the resin was carried out with a mixture of TFA : TIS : $\mathrm{H}_{2} \mathrm{O}$ in the ratio of $95: 2.5: 2.5$ for $2 \mathrm{~h}$. Excess TFA (trifluoroacetic acid) was removed by rotary evaporation. The remaining viscous PA solution was triturated with ice-cold ether and the resulting white precipitate was dried under vacuum. Characterization of PA molecules was performed with liquid chromatography-mass spectrometry (LC-MS). The mass spectrum was obtained with an Agilent LC-MS equipped with Agilent 6530 Q-TOF with an ESI source and Zorbax Extend-C18 $2.1 \times 50$ $\mathrm{mm}$ column for basic conditions and Zorbax SB-C8 $4.6 \times 100$ $\mathrm{mm}$ column for acidic conditions. A gradient of (a) water $(0.1 \%$ formic acid or $\left.0.1 \% \mathrm{NH}_{4} \mathrm{OH}\right)$ and (b) acetonitrile $(0.1 \%$ formic acid or $0.1 \% \mathrm{NH}_{4} \mathrm{OH}$ ) was used as the mobile phase. In order to purify the peptides, an Agilent preparative reverse-phase HPLC system equipped with a Zorbax Extend-C18 $21.2 \times 150 \mathrm{~mm}$ column was used for basic conditions and a Zorbax SB-C8 21.2 $\times 150 \mathrm{~mm}$ column was used for acidic conditions. A gradient of (a) water $\left(0.1 \%\right.$ TFA or $\left.0.1 \% \mathrm{NH}_{4} \mathrm{OH}\right)$ and (b) acetonitrile $(0.1 \%$ TFA or $0.1 \% \mathrm{NH}_{4} \mathrm{OH}$ ) was used as the mobile phase.

After the synthesis and purification of PA molecules, a mixture of oppositely charged PAs in aqueous environment led to self-assembly resulting in nanofiber formation. As a result of encapsulation of water by the network, gelation took place instantly, depending on the initial concentration of the PA solutions.

\subsection{Scanning electron microscope (SEM) and scanning transmission electron microscope (STEM) imaging of peptide nanofibers}

SEM imaging was carried out for observation of PA nanofiber networks. Oppositely charged PA solutions of $1 \mathrm{wt} \%$ were mixed in appropriate volume ratio (final volume being $50 \mu \mathrm{L}$ ) to produce neutral charge gels. Gels were then dehydrated by transferring to $20 \%, 40 \%, 60 \%, 80 \%$ and $100 \% \mathrm{v} / \mathrm{v}$ ethanol sequentially. Dehydrated PA gels were critical-point-dried afterwards by using Autosamdri $®$-815B (Tousimis). Dried PA networks were coated with $6 \mathrm{~nm} \mathrm{Au} / \mathrm{Pd}$ and SEM (FEI Quanta 200 FEG) images were taken by using an Everhart-Thornley 
Detector (ETD) at high vacuum mode with $15 \mathrm{keV}$ beam energy.

Samples for STEM imaging were prepared by mixing equal volumes of negatively and positively charged PA molecules with appropriate concentrations for charge neutralization and placing them on a 200-mesh carbon TEM grid for $10 \mathrm{~min}$ followed by $2 \mathrm{wt} \%$ uranyl acetate staining for $2 \mathrm{~min}$ and drying. STEM images in HAADF mode were acquired with an FEI Tecnai G2 F30 TEM at $300 \mathrm{kV}$.

\subsection{Oscillatory rheology measurement of peptide nanofiber gel stiffness}

Oscillatory rheology measurements were performed with an Anton Paar Physica RM301 Rheometer operating with a $25 \mathrm{~mm}$ parallel plate configuration at $25^{\circ} \mathrm{C}$. PA gels were prepared from equal volumes of oppositely charged PA solutions (Fig. 1a) at the concentrations below to obtain neutral charge gels with a total volume of $250 \mu \mathrm{L}$. LN-PA ( $4 \mathrm{mM}$ ) was mixed with $4 \mathrm{mM}$ GAG-PA to obtain LN-PA/GAG-PA gel, while $4 \mathrm{mM}$ K-PA was mixed with $2 \mathrm{mM}$ E-PA to obtain K-PA/E-PA gel. PA gels were incubated for $10 \mathrm{~min}$ before measurement. After equilibration, the upper plate was lowered to a gap distance of $0.5 \mathrm{~mm}$. Storage moduli $\left(G^{\prime}\right)$ and loss moduli $\left(G^{\prime \prime}\right)$ values were scanned from $100 \mathrm{rad} \mathrm{s}^{-1}$ to $0.1 \mathrm{rad} \mathrm{s}^{-1}$ of angular frequency, with $0.5 \%$ shear strain. Three samples were measured for each PA gel.

\subsection{Cell culture studies}

2.5.1. Schwann cell isolation. Schwann cells were isolated from sciatic nerves of male Sprague-Dawley rats according to a previously published protocol. ${ }^{16}$ Ten-week-old male SpragueDawley rats were used for Schwann cell isolation. All experimental procedures on animals conformed to the National Institute of Health Guide for the Care and Use of Laboratory Animals and were approved by the Animal Ethics Committee of Gulhane Military Medical Academy. Briefly, $15 \mathrm{~mm}$ sciatic nerve segments were excised, teased and cut into $2-3 \mathrm{~mm}$ fragments after removing the epineurium. Enzymatic dissociation in $0.05 \%$ collagenase was carried out at $37^{\circ} \mathrm{C}$ for $60 \mathrm{~min}$ and tissue debris was removed by passing the suspension through a $40 \mu \mathrm{m}$ cell strainer. Cells were cultured on poly-L-lysine (PLL) coated surfaces in DMEM-D-valine $\left(4.5 \mathrm{mg} \mathrm{mL}^{-1}\right.$ glucose) with $2 \mathrm{mM}$ glutamine, $10 \%(\mathrm{v} / \mathrm{v})$ fetal calf serum, $1 \%(\mathrm{v} / \mathrm{v}) \mathrm{N} 2$ supplement, $20 \mu \mathrm{g} \mathrm{mL} \mathrm{m}^{-1}$ bovine pituitary extract, $5 \mu \mathrm{M}$ forskolin, $1 \%$ penicillin/streptomycin and $0.25 \mu \mathrm{g} \mathrm{mL}^{-1}$ amphotericin B. Cells were used 19 days after isolation and within nine passages.

2.5.2. Viability of Schwann cells on peptide nanofibers. Equal volumes of $2 \mathrm{mM}$ LN-PA and GAG-PA and appropriate concentrations of E-PA $(1 \mathrm{mM})$ and K-PA $(2 \mathrm{mM})$ were used to form gels with neutral charge in 96-well plates. PA-gel coated plates were incubated at $37^{\circ} \mathrm{C}$ for $30 \mathrm{~min}$, prior to overnight incubation in a laminar flow hood at room temperature for solvent evaporation. PA matrix coated on wells was UV sterilized prior to use. Since Schwann cells are not able to attach to tissue culture plates, PLL coated surfaces were used as a control group for cell adhesion and growth. PLL coating was done on the day of the experiment, and the surface was dried for 2 hours before cell seeding. Viability analysis was performed after $48 \mathrm{~h}$ of culture by calcein-AM and ethidium homodimer 1 (EthD-1) staining. Cells were cultured on PA nanofibers and PLL coated tissue culture plates at a density of $1 \times 10^{4}$ cells per well. After $48 \mathrm{~h}$ of incubation, cell medium was discarded; cells were washed with $1 \times$ phosphate-buffered saline (PBS) and incubated with $2 \mu \mathrm{M}$ calcein-AM and $2 \mu \mathrm{M}$ ethidium homodimer-1 (EthD1) in PBS for $30 \mathrm{~min}$ at room temperature. Five random images were taken at $100 \times$ magnification from each well for both qualitative and quantitative analysis by using a fluorescence microscope. Cells were counted from images obtained with NIH ImageJ software.

2.5.3. SEM imaging of Schwann cells on PA nanofiber and PLL coated surfaces. The morphology and spreading of Schwann cells were examined by SEM imaging. Glass

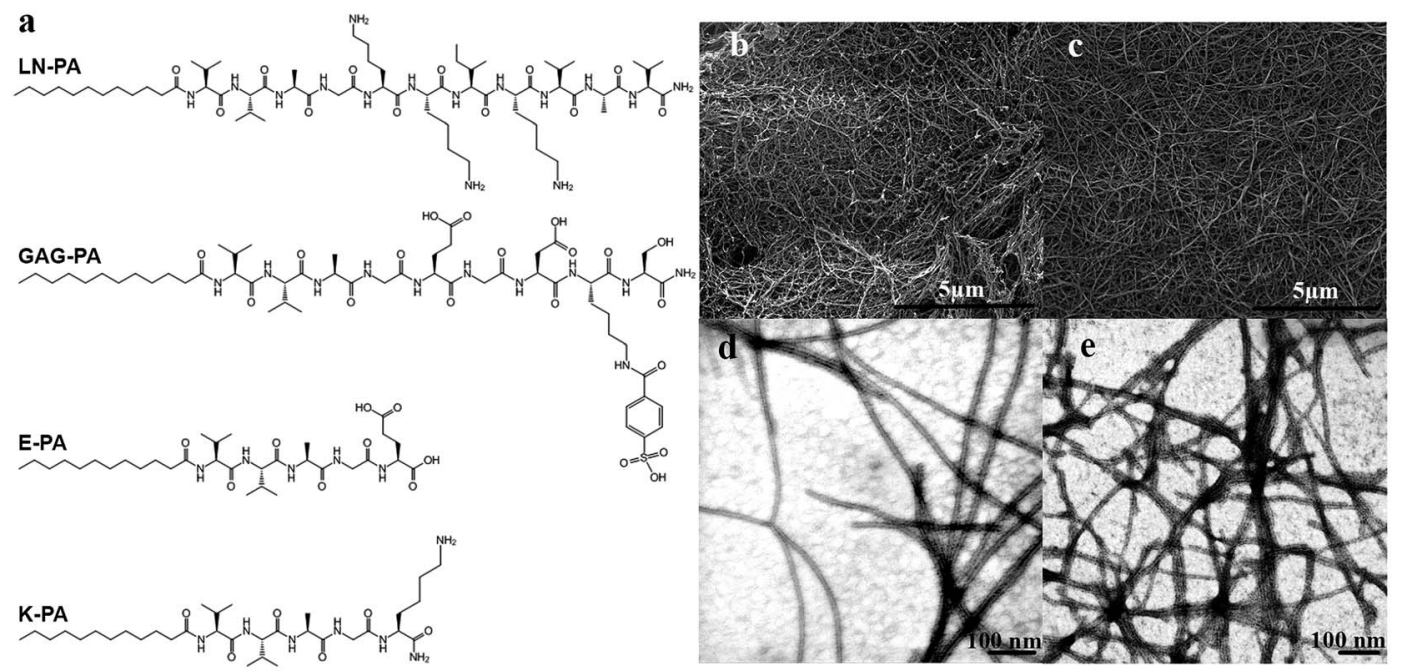

Fig. 1 (a) Chemical structures of PA molecules used in the study. SEM images of LN-PA/GAG-PA (b) and K-PA/E-PA (c) show nanofiber networks resembling the fibrous ECM structure. Individual nanofibers in LN-PA/GAG-PA (d) and K-PA/E-PA (e) gels were observed by TEM imaging. 
coverslips (13 mm) placed in 24-well plates were coated with PA nanofibers and PLL solutions as described above. Cells were seeded on top of the coated surfaces at a density of $2.5 \times$ $10^{4}$ cells per well. After $48 \mathrm{~h}$ of incubation, cells were rinsed with PBS and fixed with $2 \%$ glutaraldehyde/PBS and $1 \mathrm{wt} \%$ $\mathrm{OsO}_{4}$ for $1 \mathrm{~h}$ each, respectively. Fixed cells were washed with water and dehydrated sequentially in $20 \%, 40 \%, 60 \%, 80 \%$, and $100 \%$ ethanol. Samples were critical point dried with Autosamdri-815B (Tousimis). Dried samples were coated with $6 \mathrm{~nm} \mathrm{Au} / \mathrm{Pd}$, and SEM (FEI Quanta $200 \mathrm{FEG}$ ) images were taken by using an ETD detector in high vacuum mode with $15 \mathrm{keV}$ beam energy.

2.5.4. Immunocytochemistry. Glass coverslips $(13 \mathrm{~mm})$ placed in 24-well plates were coated with PA nanofibers and PLL as described above. Schwann cells were seeded on top of the coated surfaces at a density of $2.5 \times 10^{4}$ cells per well. After $48 \mathrm{~h}$ of incubation, cells were fixed with $4 \%$ paraformaldehyde in PBS for $15 \mathrm{~min}$ at room temperature and treated with $0.3 \%$ Triton X/PBS (PBS-Tx 0.3\%) for $15 \mathrm{~min}$. After washing with PBS, blocking was carried out with $10 \%$ goat serum and $1 \%$ bovine serum albumin (BSA) in PBS with $0.3 \%$ Triton-X for $30 \mathrm{~min}$. Cells were then treated with primary antibody against S100 (Millipore, 04-1054) at 1:100 dilution and incubated overnight at $4{ }^{\circ} \mathrm{C}$. After washing with PBS several times, cells were incubated with goat anti-rabbit IgG H\&L (DyLight@ 488) preadsorbed (Abcam, ab96899) secondary antibody for $1 \mathrm{~h}$ at room temperature and they were washed with PBS several times. Coverslips were then mounted with Prolong Gold Antifade Reagent (Invitrogen) and sealed with nail polish. Samples were imaged with confocal microscopy (Zeiss LSM510).

2.5.5. Analysis of nerve growth factor (NGF) secretion by Schwann cells. MaxiSorp plates for ELISA were coated with primary antibody specific to NGF. Antibody dilution (1:125) was performed with assay buffer. After coating with primary antibody, plates were incubated overnight at $4{ }^{\circ} \mathrm{C}$. Solutions were discarded next day and the wells were washed with washing buffer (Tween 20 in $0.9 \%$ (w/v) $\mathrm{NaCl}$ solution). After drying by tapping, blocking was carried out with $1 \times$ assay buffer for 2 h. Blocking was followed by addition of NGF (500 $\mathrm{ng} \mathrm{mL}{ }^{-1}$ ) and culture medium to compare the NGF release from Schwann cells seeded on PA nanofiber and PLL coated surfaces after $48 \mathrm{~h}$. The plates were incubated overnight at $4{ }^{\circ} \mathrm{C}$. The next day, solutions were removed and the wells were washed with washing buffer 5 times. After drying by tapping, biotinylated antibody against NGF (1: 500 dilution) was added and incubated for $2 \mathrm{~h}$. After incubation, the wells were washed with washing buffer 5 times and dried by tapping. Streptavidin-linked horseradish peroxidase (HRP) was added and incubated for $1 \mathrm{~h}$. Then, solutions were removed and the wells were washed with washing buffer 5 times. After drying, 3,3' ,5, $5^{\prime}$-tetramethylbenzidine (TMB) was added and the plates were incubated until a bright blue color was obtained. The reaction was stopped with stop solution, and absorbance was measured by using a Spectramax M5 microplate reader at $450 \mathrm{~nm}$ wavelength. This value was subtracted from the reference value (650 nm).

\subsection{In vivo studies}

2.6.1. Surgical procedures. Ten-week-old male SpragueDawley rats were used under the approval of the Animal Ethics Committee of Gulhane Military Medical Academy. Twenty-eight rats were divided into four experimental groups with seven rats each. All rats were operated on under xylazine and ketamine (80 $\mathrm{mg} \mathrm{kg}^{-1}$ ) anesthesia. Sciatic nerves were exposed by skin and muscle incision (gluteal split technique) and a $10 \mathrm{~mm}$ nerve gap was created $5 \mathrm{~mm}$ distal to the sciatic notch. A $15 \mathrm{~mm}$ nerve conduit was sutured to transected nerve ends by inserting $2.5 \mathrm{~mm}$ nerve segments from both proximal and distal end into the tube and leaving a $10 \mathrm{~mm}$ gap. After suturing the conduit, PA gels with neutral charge were formed in situ by injecting $100 \mu \mathrm{L}$ of each PA solution, with a total volume of $200 \mu \mathrm{L}$. Two oppositely charged PA solutions were injected into the tube with two different injectors at the same time. LN-PA/GAG-PA gel was used for biofunctionalization of biologically inert conduits while K-PA/E-PA gel was used as an epitope-free control. To obtain a neutral charged PA gel, $4 \mathrm{mM}$ LN-PA was mixed with 4 mM GAG-PA and 4 mM K-PA was mixed with $2 \mathrm{mM}$ E-PA at equal volumes. PAs were dissolved in isotonic sucrose $(0.25 \mathrm{M})$ solution. Nerve conduits filled with sucrose were used as non-treated conduit controls (S). For autograft treated animals (A), excised nerve tissues were reversed and sutured back to nerve stumps. Surgical operations were performed on the sciatic nerve of right hind limbs, and left limb sciatic nerves were used as healthy controls.

2.6.2. Walking track analysis. Twelve weeks after the surgery, walking track analysis was performed as described previously. ${ }^{17}$ Briefly, hind paws were ink stained and rats were allowed to walk in an $8 \mathrm{~cm} \times 43 \mathrm{~cm}$ wooden walking path with a dark box at the end of the path. Footprints were analyzed to calculate sciatic functional index from the following parameters: PL (paw length), the distance between the top of the third toe and the bottom of the heel; TS (toe spread), the distance between the first and the fifth toe; and IT (internal toe spread), the distance between the second and fourth toe. All measurements were carried out for both experimental (right) and normal (left) limbs. Parameters obtained from the experimental limb were denoted EPL, ETS and EIT while those from the normal limb were called NPL, NTS and NIT, and sciatic functional index (SFI) was calculated for each animal by using the following formula:

$$
\begin{gathered}
\mathrm{SFI}=109.5(\mathrm{ETS}-\mathrm{NTS}) / \mathrm{NTS}-38.3(\mathrm{EPL}-\mathrm{NPL}) / \mathrm{NPL} \\
+13.3(\mathrm{EIT}-\mathrm{NIT}) / \mathrm{NIT}-8.8
\end{gathered}
$$

2.6.3. Electrophysiological assessment. For nerve conduction study, an electromyography (EMG) device (Medelec Synergy, USA) with $(2+8)$ channels was used. Both sciatic nerves were explored. Supramaximal stimulus was given just proximal of the incision area of sciatic nerve in the rat's right leg and at the same place relative to the left sciatic nerve in the healthy leg, and the data were recorded with needle electrodes from soleus muscles. Both latency and amplitude of the sciatic nerve were measured. Latency differences were obtained by subtracting the 
intact sciatic nerve latency from the operated sciatic nerve latency. The percentage recovery rate was determined by dividing the amplitude of the intact sciatic nerve into the operated sciatic nerve amplitude.

2.6.4. Histological assessment. Sciatic nerves were harvested after EMG measurement at 12 weeks and each harvested nerve was dissected into three parts named proximal, midtissue and distal (Fig. S3†). Mid-tissue was a $2 \mathrm{~mm}$ segment obtained from the middle part of the graft and it was fixed in $2.5 \%$ glutaraldehyde. After post-fixation with $2 \mathrm{wt} \% \mathrm{OsO}_{4}$ for $4 \mathrm{~h}$, mid-tissues were embedded in Araldite resin. Semi-thin (1 $\mu \mathrm{m})$ transverse sections were used for toluidine blue staining and images were taken under a light microscope. Ultrathin sections $(80 \mathrm{~nm})$ on copper were stained with uranyl acetate and lead citrate. Morphological assessment of the specimens was performed by using an FEI Tecnai G2 F30 transmission electron microscope operating at $80 \mathrm{kV}$, and axonal diameters of myelinated fibers were quantified using ImageJ software. Proximal and distal segments were fixed with $10 \%$ formalin and embedded in paraffin. Longitudinal sections $(4 \mu \mathrm{m})$ were used for hematoxylin-eosin staining and immunohistochemistry. Sections were deparaffinized in xylene and rehydrated in an ethanol series for hematoxylin-eosin staining according to the standard protocol. For immunohistochemistry experiments, sections were stained with anti- $\beta$ III tubulin $(1: 100$, Millipore 04-1049) and anti-S100 (1 : 250, Millipore 04-1054) antibodies. After primary antibody staining, horseradish peroxidase conjugated goat anti-rabbit secondary antibody was used followed by 3,3'-diaminobenzidine staining. All samples were mounted onto glass slides using xylene based mounting medium. Digital images were acquired via a Zeiss Axio Scope A1.

\subsection{Statistical analysis}

Statistical analyses were performed using one-way ANOVA with Bonferroni multiple comparison test. A $p$-value of less than 0.05 was considered statistically significant. $\left({ }^{*} p<0.05 ;{ }^{*} p<0.01\right.$; $* * * p<0.001)$. Error bars indicate standard error of the mean.

\section{Results}

\subsection{Synthesis and characterization of peptide nanofiber gels}

Two different peptide amphiphiles (PAs) with collaboratively working bioactive epitopes were synthesized, characterized and used for biofunctionalization of nerve guidance conduits (Fig. 1a). LN-PA contains a laminin derived short peptide "IKVAV" while GAG-PA mimics growth factor binding ability of heparan sulfate glycosaminoglycans through hydroxyl, carboxylic acid and sulfonate groups presented on side chains of the amino acids in the sequence. These two PA molecules are oppositely charged and form a self-supporting LN-PA/GAG-PA gel upon mixing, by charge neutralization and hydrophobic collapse. As physical guidance is also important in axonal elongation and pathfinding, a control peptide nanofiber gel, named K-PA/E-PA, was also used. K-PA/E-PA consists of two peptide amphiphile molecules without bioactive epitopes. K-PA contains a lysine and E-PA contains a glutamic acid for charge incorporation instead of the bioactive epitopes present in LN-PA and GAG-PA (Fig. 1a). TEM imaging revealed that LN-PA/GAGPA and K-PA/E-PA gels were revealed to have similar nanofiber structures. Individual nanofibers within both hydrogels have diameters of 8-10 $\mathrm{nm}$ (Fig. 1d and e). Nanofiber networks formed by these PA nanofibers are also quite similar to that of natural ECM as evidenced by SEM imaging (Fig. $1 \mathrm{~b}$ and c). ${ }^{18}$

\subsection{Viability of Schwann cells and their interactions with PA nanofibers}

Since Schwann cells are crucial for peripheral neural regeneration, viability of Schwann cells cultured on peptide nanofibers or PLL coated surfaces was assessed by calcein-AM and ethidium homodimer staining after $48 \mathrm{~h}$ of culture. Cell viability was comparable on both surfaces, with no statistically significant difference. This indicates that peptide nanofibers are biocompatible with these cells (Fig. 2). Interaction of Schwann cells with the surrounding microenvironment was assessed by SEM imaging (Fig. 3a-c). SEM images revealed that Schwann cells on LN-PA/GAG-PA scaffold display a characteristic morphology that is different from that of the cells cultured on control peptide nanofibers and PLL coated surfaces. Cells spread better on the bioactive scaffold and interaction between cells was also at a higher level compared with control groups. The effect of PA nanofibers on cells was further analysed through immunofluorescence staining against S100 protein (Fig. 3-f). Confocal images also showed that bioactive nanofibers (LN-PA/GAG-PA) induced more interactions between cells and cells adhered firmly onto the scaffold.

\subsection{NGF secretion from Schwann cells was increased when seeded on bioactive nanofiber scaffold}

In order to analyze the effect of peptide nanofibers on functionality of Schwann cells, ELISA test was performed to determine the extracellular accumulation of NGF released by Schwann cells incubated on peptide nanofibers and PLL coated surfaces for $48 \mathrm{~h}$. The NGF level secreted by Schwann cells was increased in the LN-PA/GAG-PA group by almost 2.0 -fold compared with both K-PA/E-PA and PLL coated surfaces (Fig. 4). The results showed that bioactive LN-PA/GAG-PA scaffold promotes secretion of NGF as compared with the control surfaces.

\subsection{Bioactive peptide nanofibers promote functional recovery of sciatic nerve injury}

The in vivo effects of peptide nanofibers on neural regeneration were assessed 12 weeks after full transection of the sciatic nerve (Fig. 5a). Motor behavior recovery was determined by sciatic functional index (SFI) measurements deduced from walking track analysis (Fig. 5d). Fully recovered sciatic nerve transmits motor signals to the paws, allowing toe opening and full pressure to be applied by the paw, leading to a normal walking pattern of footprints. SFI values closer to zero indicate better functional regeneration while those close to -100 indicate worse regeneration, if any at all. Biofunctionalized nerve conduit treatment resulted in best functional outcome; 

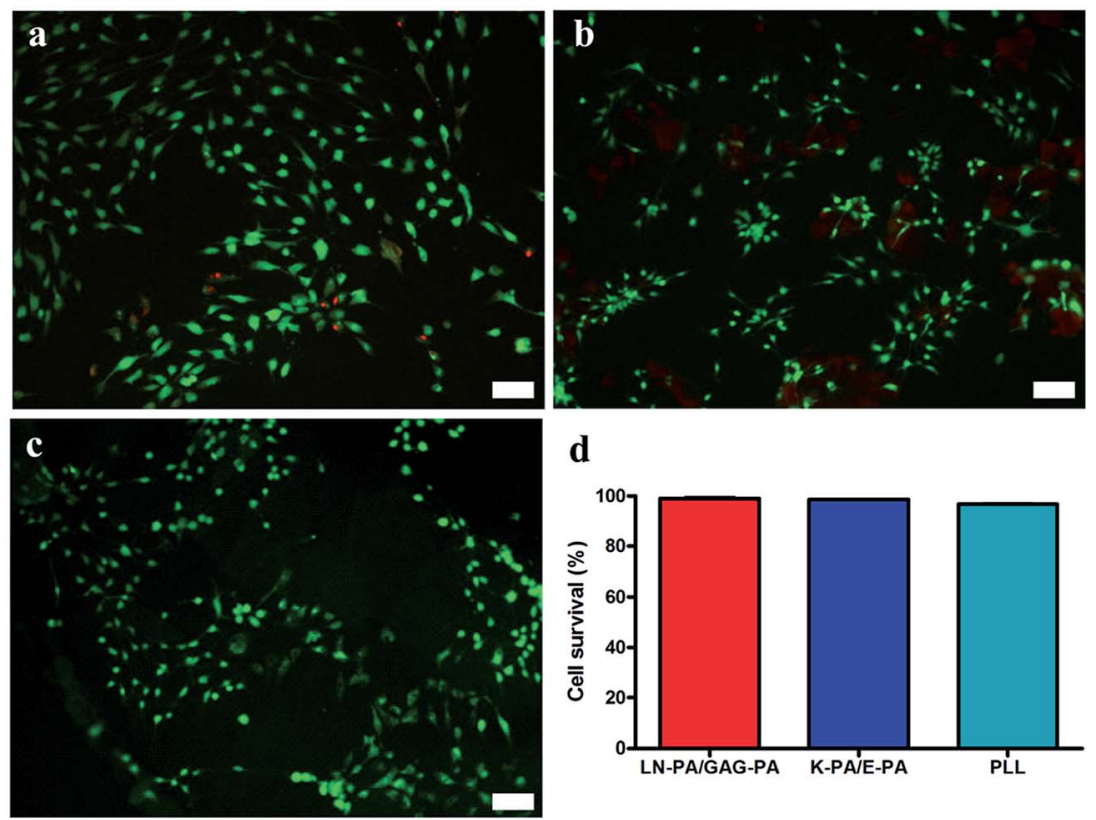

Fig. 2 Viability of Schwann cells on poly-L-lysine (PLL) coated surface (a), K-PA/E-PA scaffold (b) and LN-PA/GAG-PA scaffold (c) analyzed by live-dead assay after $48 \mathrm{~h}$ of incubation. Relative cell viability (d) showed that Schwann cells adapted to PA scaffolds and have comparable viability with PLL-coated surface at the end of $48 \mathrm{~h}$. Scale bars are $100 \mu \mathrm{m}$.

however, the differences were not statistically significant owing to high variation within the groups (Fig. 5e). When nerve conduits were filled with control peptide nanofiber gel, mean results were similar to those from the bioactive gel filled conduits, both being better than either empty conduit or autograft. Nevertheless, analyzing SFI values from each rat indicates quite well recovered individual rats within the LN-PA/ GAG-PA filled conduit treated group. SFI values of these rats are much closer to zero and much better than those within other groups. The number of rats eliminated from walking track
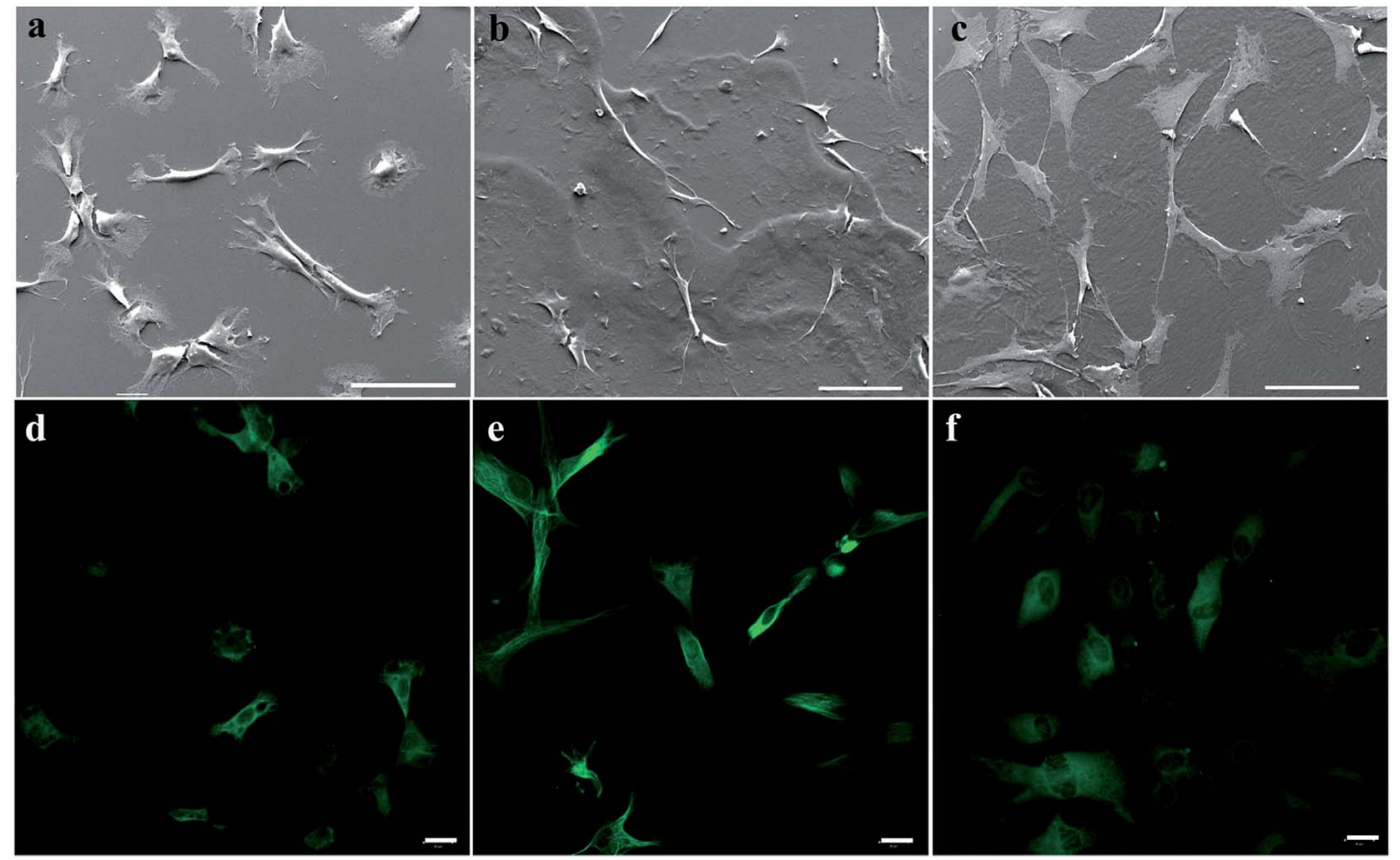

Fig. 3 PA substrates are biocompatible and support adhesion of Schwann cells. SEM and S100-immunostained confocal images of Schwann cells cultured on PLL ( $a$ and d), K-PA/E-PA ( $b$ and e) and LN-PA/GAG-PA ( $c$ and f) gels. Images were obtained after $48 \mathrm{~h}$ of incubation. Scale bars are $100 \mu \mathrm{m}$ for SEM images and $20 \mu \mathrm{m}$ for confocal images. 


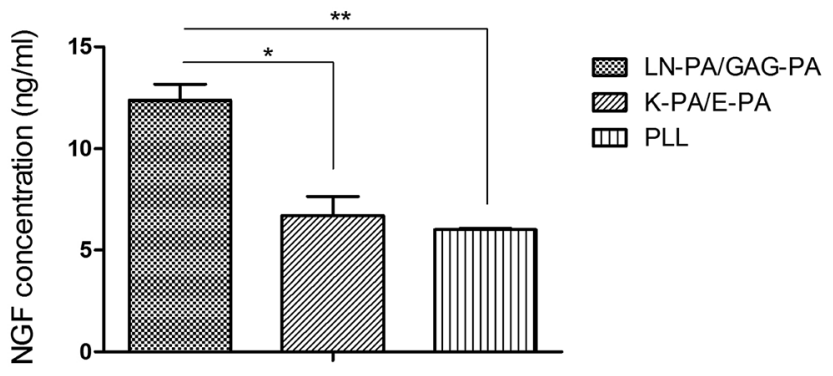

Fig. 4 NGF release from Schwann cells cultured on LN-PA/GAG-PA, K-PA/E-PA and PLL coated surfaces after $48 \mathrm{~h}$ of incubation. Values represent mean $\pm \operatorname{SEM}(* * p<0.01, * p<0.05)$.

analysis owing to self-chewing of their digits is an indirect measurement of lack of sensory recovery. Digit loss was observed in a high number of animals treated with empty conduits and autograft while almost none was observed in animals treated with peptide nanofiber filled conduits (Table $\mathrm{S} 1 \dagger)$. These results indicate that filling the conduit with peptide nanofibers leads to better sensory and motor recovery compared with the use of an empty conduit, and even compared with autograft treatment.

Electromyography (EMG) was performed for quantitative assessment of signal transmission through regenerated nerves. Stimulating muscles proximal to the transected nerve section results in receiving signals from end target muscles when properly myelinated regenerating axons reach to the target organ. Two measures are used to detect functional recovery by EMG: amplitude shows the size of the action potentials transmitted through the regenerated axon fibers, while latency shows the time it takes for signals to reach the end target. The higher the amplitude and the shorter the latency, the better is the electrical signal transmission through the nerve. EMG results were coherent with SFI measurements. Use of conduits biofunctionalized with LN-PA/GAG-PA gel showed significant improvement in amplitude compared with use of empty conduits and autograft treatment. Epitope-free control K-PA/EPA gel also led to higher amplitudes than empty conduits and autograft but the differences were not statistically significant (Fig. 5b). Latency measurements indicated a delay in signal transmission in nerves repaired with empty conduits and autografts and a faster transmission when conduits were filled with peptide nanofibers (Fig. 5c).

\subsection{Bioactive peptide nanofibers support tissue integrity and neural regeneration in sciatic nerve injury}

In order to further investigate the effect of LN-PA/GAG-PA functionalization of the conduit on regenerating tissue, a detailed histological analysis was carried out. Excised tissues were dissected into three parts (Fig. S3†). Three-millimeter tissue segments from the center of conduits and autografts were processed for ultrastructure imaging by TEM and toluidine blue staining for detailed analysis of myelination. Proximal and distal tissues were analyzed to deduce the extent of axonal

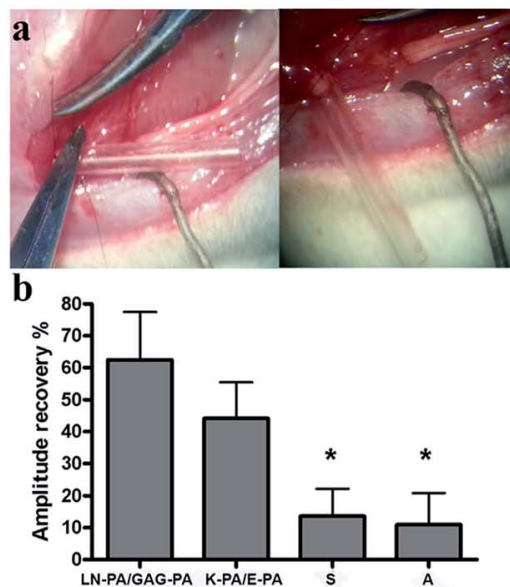

c

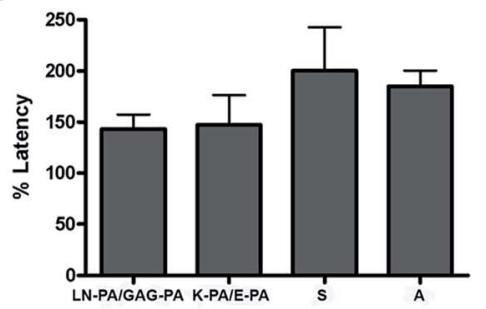

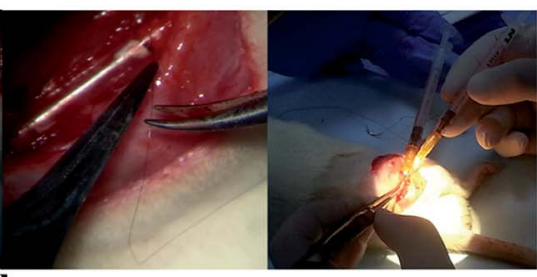

d
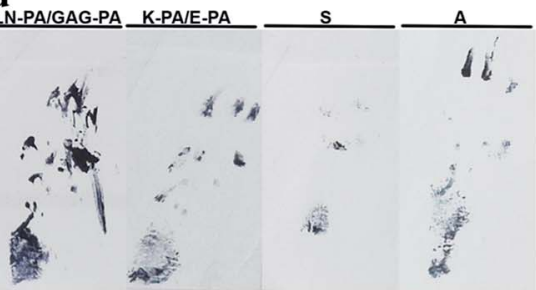

e

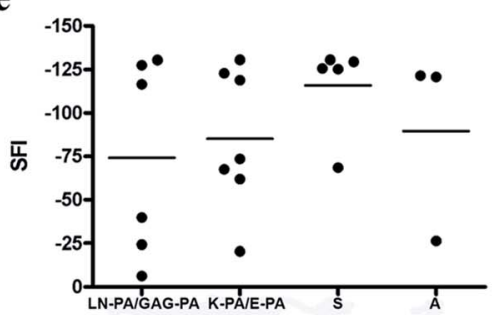

Fig. 5 Images of surgical operation showing the suturing of the conduit and in situ formation of PA gels within the conduit lumen (a). EMG results indicate a higher amplitude (b) and a lower latency (c) in peptide nanofiber filled conduits. SFI values (e) measured from footprints (d) obtained during walking track analysis indicate a better improvement in motor function in LN-PA/GAG-PA biofunctionalized conduit treated rats. A: Autograft and S: sucrose filled conduit treated groups. 
elongation and density of the elongated axons. In addition, Schwann cell population of elongated axons was also investigated in consideration of the importance of these cells in myelination of newborn nerves.

Overall morphology of the repaired nerves was deduced from observation of hematoxylin-eosin (H\&E) stained tissues (Fig. 6). Good linear ordered structure was observed in all treatment groups in the proximal segment. This indicates a healthy axonal elongation from the proximal stump of the transected nerve to the center of the $10 \mathrm{~mm}$ nerve gap produced by transection. However, when the nerve segments closer to the distal stump were analyzed, it was clear that nerves elongated further and reached to the distal stump when conduit lumen was filled with peptide nanofibers. A closer view of the distal stump revealed that conduits filled with LN-PA/GAG-PA nanofibers enhanced axonal regeneration even more than those filled with control KPA/E-PA nanofibers. Axon density and integrity were better in LN-PA/GAG-PA filled conduits in the distal stump compared with those in K-PA/E-PA filled conduits. Images obtained at higher magnification also provide information about the integration of the newborn nerves in the far distal region. Signs of Wallerian degeneration are clear in nerves in the far distal region for all nerves except those treated with LN-PA/GAG-PA filled conduits. Though not as perfect as those in the proximal segment, nerve fascicles also showed linear orientation in the distal segment when LN-PA/GAG-PA biofunctionalized

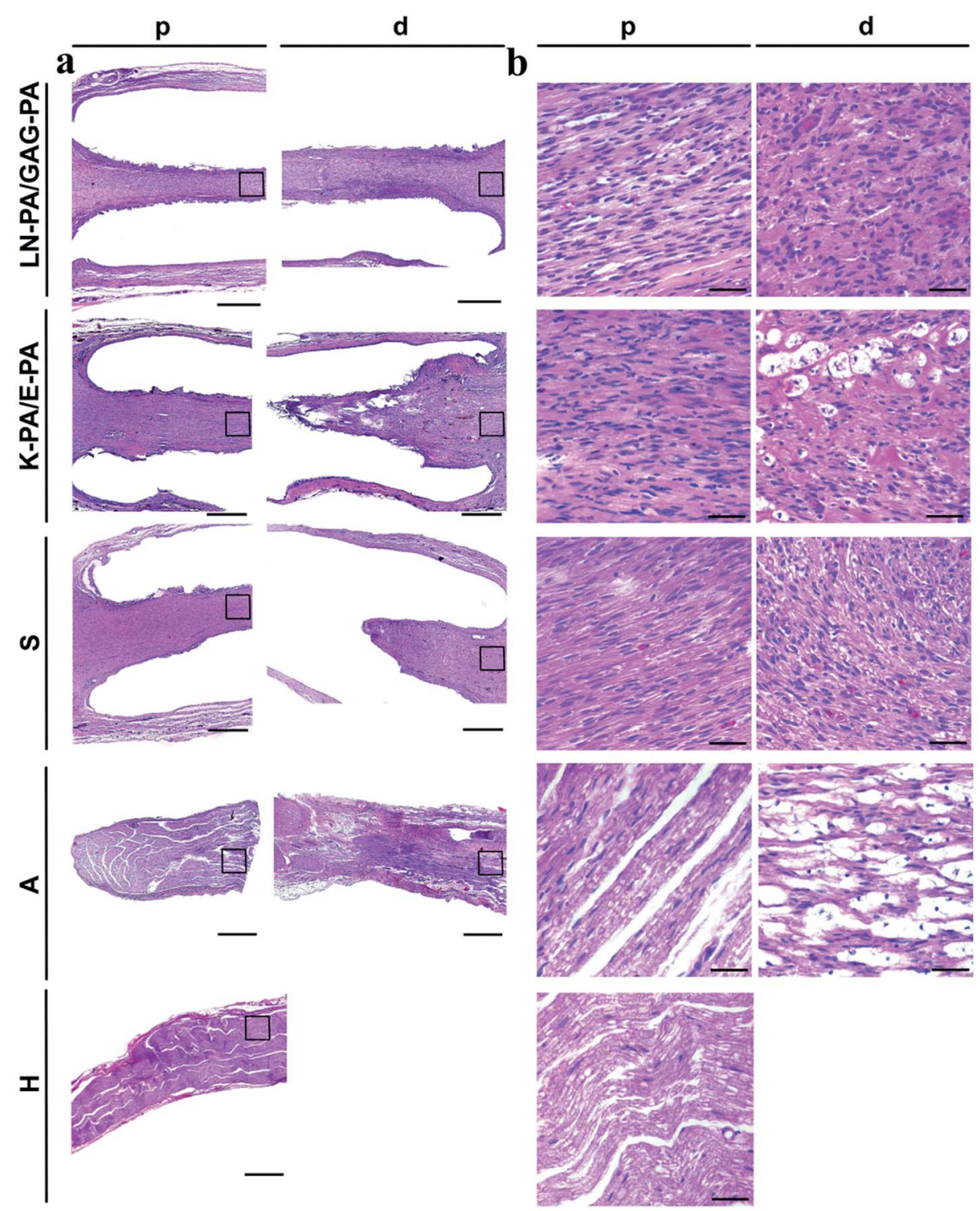

Fig. 6 Hematoxylin-eosin (H\&E) staining (a) of excised tissues indicates a better axonal elongation within LN-PA/GAG-PA functionalized conduits. Regenerating axons could reach the distal stump in LN-PA/GAG-PA treated nerves while incomplete regeneration was evident in all other groups (scale bars are $200 \mu \mathrm{m}$ ). Higher magnification $(400 \times)$ images $(b)$ indicate renervation in the far distal region in all treatments except LN-PA/GAG-PA functionalized conduits, where good linear ordered tissue structure without any sign of renervation is clearly seen (scale bars aare $40 \mu \mathrm{m}$.). $\mathrm{p}$ indicates the proximal tissue and d indicates the distal tissue. A: autograft, $\mathrm{H}$ : healthy tissue and $\mathrm{S}$ : sucrose filled conduit treated groups. 
conduits were used. This linear orientation seems to be hampered in all other treatments applied. Besides, there is no sign of gaps caused by denervation in LN-PA/GAG-PA filled conduit treated nerves, which are clearly present in all other treatment groups, including autografts.

Staining nerves for $\beta$-III-tubulin (Fig. 7a) and S100 (Fig. 7b) further proved the better regeneration in nerves treated with LN-PA/GAG-PA biofunctionalized conduits. The more condensed $\beta$-III-tubulin staining pattern in this group indicates that a higher number of axons recovered and elongated in the presence of laminin and GAG mimetic cues. This is observed not only in the proximal segment but also in the far distal segment, showing that elongating axons reached far beyond the distal injury site. Observation of insufficient renervation and discontinuity in the nerves treated with autografts, empty or control K-PA/E-PA filled conduits was also in good correlation with H\&E staining results; however, the differences between groups were more evident in $\beta$-III-tubulin stained tissues.

Presence of Schwann cells around axons is an important characteristic structure of healthy peripheral nerves and it is
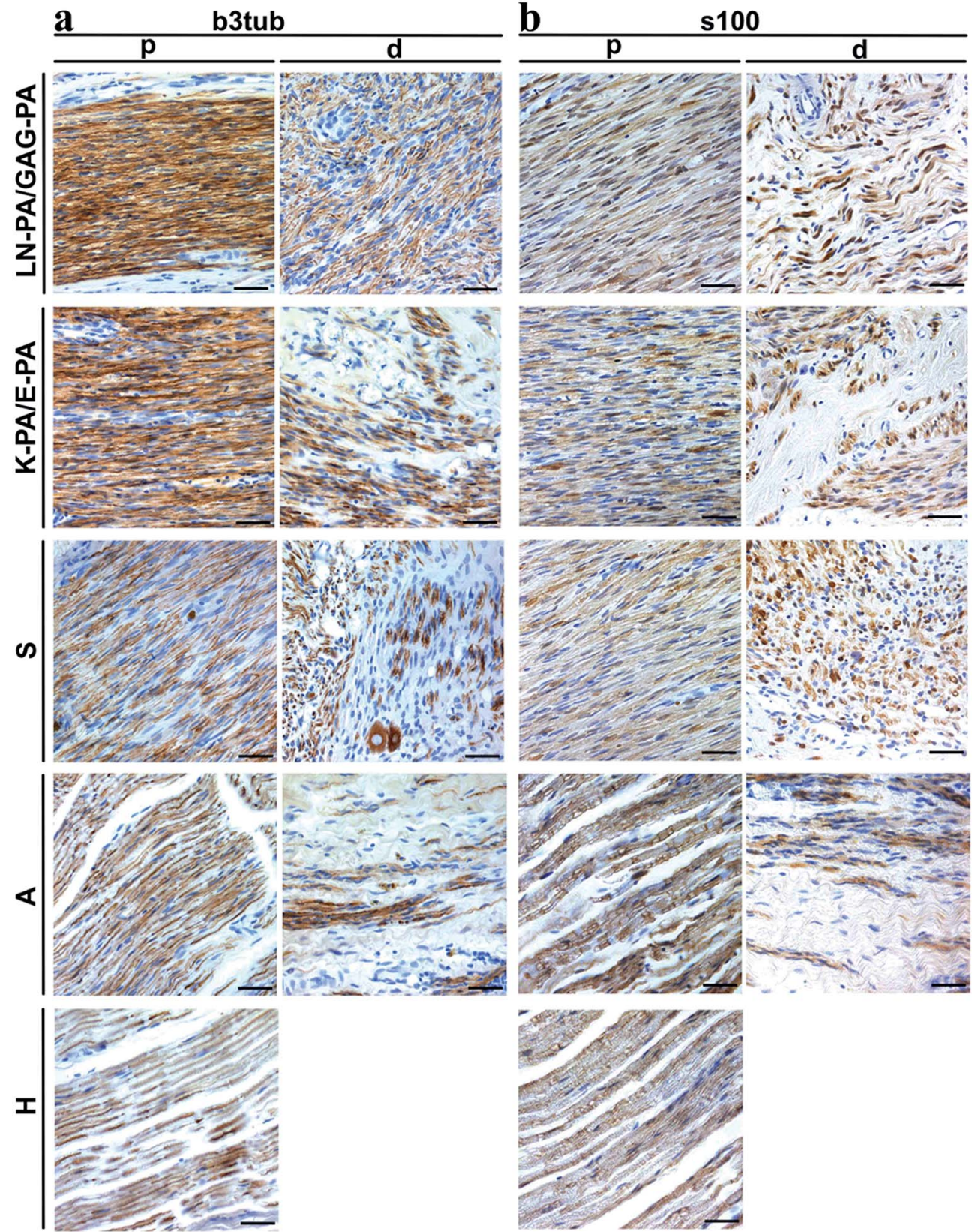

Fig. $7 \quad \beta$-III-Tubulin staining (a) indicates a densely packed nerve tissue formation with good linear ordered structure in the proximal region in LN-PA/GAG-PA treated nerves. Renervation at distal region is observed in all tissues except LN-PA/GAG-PA functionalized conduit treatment. Higher magnification $(400 \times)$ images of Schwann cell staining against S100 (b) show higher numbers of Schwann cells exerting linear alignment in LN-PA/GAG-PA treated nerves in the distal region. $p$ indicates the proximal tissue and $d$ indicates the distal tissue (the scale bars are $40 \mu m$ ). A: autograft, $\mathrm{H}$ : healthy tissue and $\mathrm{S}$ : sucrose filled conduit treated groups. 
required for proper myelination. Any disruption in the myelination hampers the motor and sensory functions of the nerve, leading to a loss of function in the target organ. Schwann cells in regenerating nerves were visualized by staining with antiS100 antibody. Newborn nerves in the proximal segment were found to be populated by Schwann cells showing an aligned pattern for all groups, which is a characteristic of peripheral nerves. This indicates that elongated axons can potentially be myelinated, providing a healthy signal transmission. However, the distal segment of the nerve should also hold properly positioned Schwann cells since the continuity in Schwann cell alignment on nerve fibers is crucial for the restoration of the nerve conduction pathway. When S100 stained tissues were analyzed it was clear that even if the Schwann cells were placed on axons at proximal regions, this could not be achieved at distal regions, except for LN-PA/GAG-PA treated nerves. Schwann cells did not populate the distal regions, and consequently, elongating nerves also did not integrate successfully in other treatment groups. This is most clear in autograft treatment, for which the proximal segment is similar to the healthy tissue in both $\beta$-III-tubulin stained nerve fascicles and S100 stained Schwann cells on the nerves, but the distal segment is quite different from the healthy tissue.

\subsection{Bioactive peptide nanofibers promote myelination of axons after sciatic nerve gap repair}

Myelination of newborn nerves is essential for complete regeneration of injured nerves. Although presence of Schwann cells is crucial for regeneration and might indicate myelination, their mere presence is not a proof of myelination. To analyze myelination pattern in regenerated nerves, toluidine blue staining and ultrastructure analysis by TEM imaging were performed. Analysis of toluidine blue stained nerve sections showed the homogeneous distribution of myelinated axons in LN-PA/GAG-PA functionalized conduits and autografts (Fig. 8a and d) compared to healthy controls (Fig. 8e). On the other hand, myelinated axons with abnormal morphologies were

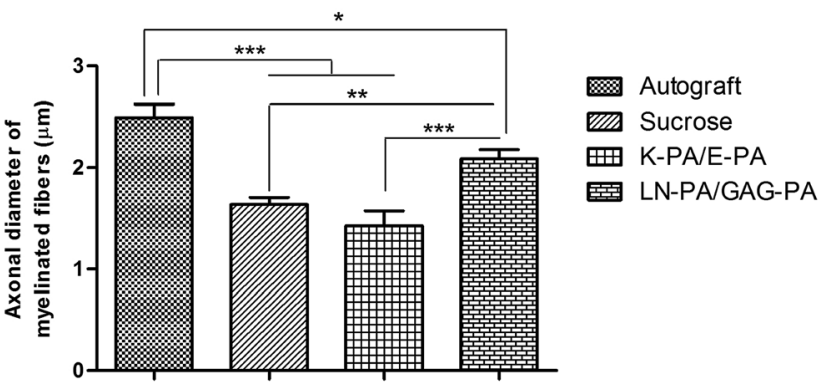

Fig. 9 Axonal diameters of myelinated fibers in different experimental groups. Values represent mean $\pm \operatorname{SEM}\left({ }^{*} p<0.05,{ }^{* *} p<0.01, * * * p<\right.$ 0.001).

observed in all treatment groups except LN-PA/GAG-PA treated nerves. Nerves treated with K-PA/E-PA filled conduits showed both areas that completely lacked myelinated nerves and some dense areas with a high number of myelinated axons (Fig. 8b).The morphological examination of autograft treatment group revealed that Schwann cells were surrounded by onion-bulb-like structures which are a characteristic sign of demyelination and axonal degeneration. Swollen axons were also clearly observed in empty conduit treated nerves (Fig. 8c). Ultra-thin sections were investigated under the transmission electron microscope. The results showed the thickness of the myelin sheath around the axons was the greatest for native nerves, followed by autograft and LN-PA/GAG-PA treated groups at week 12 after injury (Fig. $8 \mathrm{f}-\mathrm{j}$ ). Images also revealed that the thickness of the myelin sheaths in K-PA/E-PA and sucrose treated groups was less than in the other groups (Fig. $8 \mathrm{~g}$ and $\mathrm{h}$ ). The quantitative analysis also showed that the axonal diameter of the myelinated fibers was significantly larger in the LN-PA/GAG-PA treated group compared with the sucrose and K-PA/E-PA groups (Fig. 9).

\section{Discussion}

Synthetic nerve guidance conduits are hollow tubes that provide isolation of injured nerve ends from the surrounding
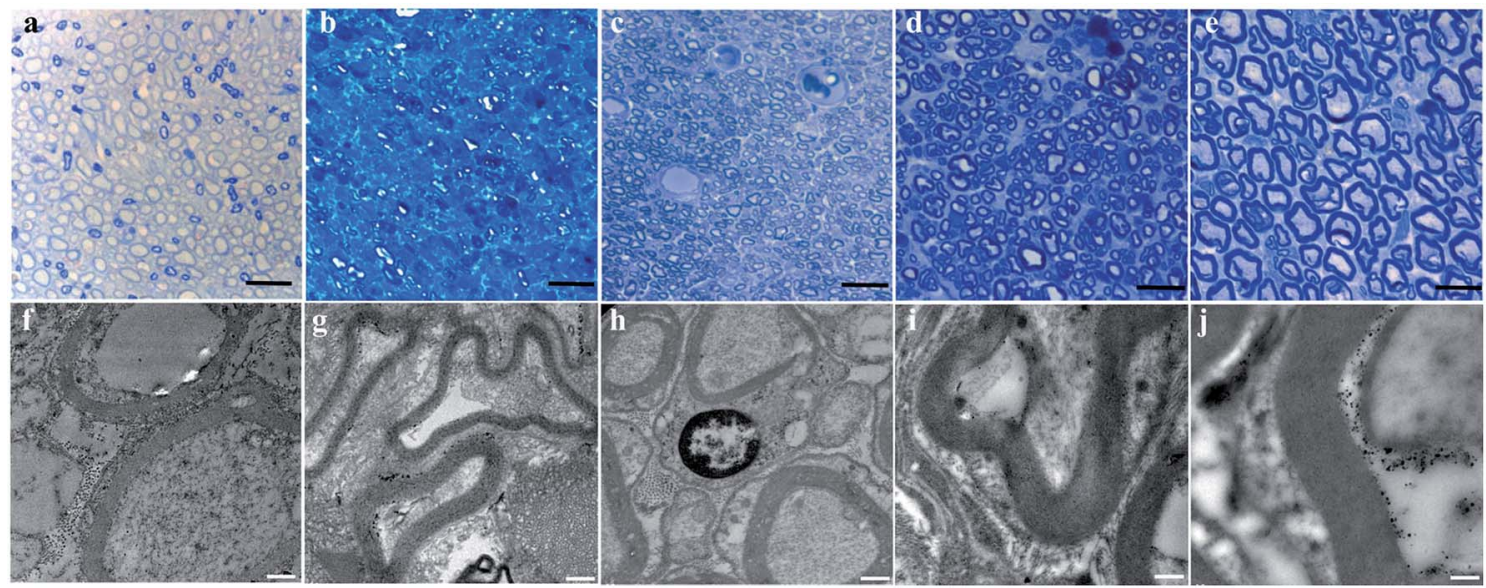

Fig. 8 Toluidine blue-O staining and TEM images of transverse sections of resin embedded tissues. LN-PA/GAG-PA (a and f), K-PA/E-PA (b and $\mathrm{g}$ ), sucrose filled conduit treated ( $\mathrm{c}$ and $\mathrm{h}$ ), autograft ( $\mathrm{d}$ and i) and healthy (e and j) groups. Scale bars are $100 \mu \mathrm{m}$ for toluidine blue staining and $500 \mathrm{~nm}$ for TEM images. 
connective tissue, prevent fibroblast infiltration and scar tissue formation and provide an appropriate environment for axonal elongation. In addition, they function as a guidance channel for the newly elongating axons from the proximal stump to find the distal stump which is crucial for prevention of painful neuromas which are common in untreated peripheral nerve injuries..$^{19}$ Although NGCs are considered an alternative therapy for long gap nerve transections without harvesting a nerve from a donor site, therapeutic success is not yet as high as desired. Most research on peripheral nerve regeneration has focused on the development of nerve conduits for guided nerve regeneration. Different approaches have been used in order to enhance the regeneration capacity across the peripheral nerve gaps. Growth-permissive substrates such as hydrogels, neurostimulatory ECM proteins or peptides, trophic factors including bFGF, NGF and BDNF, and supportive cells such as glial cells, Schwann cells or stem cells have been used to promote growth and regeneration of peripheral nerves..$^{20,21}$ While designing a material for peripheral nerve regeneration, it is important to consider the desired biochemical and physical properties and use a combination of various modifications in order to increase the therapeutic potential of the material. Also, incorporation of biological functional groups can provide additional benefit for axonal recovery considering that the axonal development occurs not in a hollow tube but in an environment full of biological signals that work in a collective manner. These signals are normally provided by ECM molecules, growth factors, cytokines and nearby cells secreting these factors in the peripheral nerves. Herein, we combined both physical and biochemical properties of peptide amphiphiles through modification of mechanical properties and including two different bioactive epitopes to mimic the natural ECM of nerve tissue, ultimately to obtain dual effect for peripheral nerve regeneration. NGCs were functionalized by filling the lumen with bioactive peptide nanofiber gels that could mimic the fibrous ECM structure along with presenting the neuroregenerative effect of laminin and an inductive effect on growth factors, which are essential for axonal regeneration.

Functional evaluation analysis of the treatments by SFI measurements led us to conclude that the functional outcome is improved when transected sciatic nerves are treated with peptide nanofiber filled conduits, compared with those treated with empty conduits or autografts. Bioactive signals incorporated in LN-PA/GAG-PA gel result in higher amplitudes and better SFI values compared with control K-PA/E-PA gels. This indicates the presence of a more complete signal transmission in nerves treated with LN-PA/GAG-PA biofunctionalized conduits.

Laminin is important not only in neurite outgrowth but also in Schwann cell differentiation and myelination of newly elongating axons., ${ }^{9,22}$ It is also known that ablation of laminin impairs Schwann cell proliferation. ${ }^{23}$ Higher numbers of Schwann cells can dedifferentiate and turn into the proliferating state in the presence of laminin derived IKVAV sequence, resulting in a higher number of Schwann cells for initiation of Wallerian degeneration. This in turn might recruit macrophages in higher numbers and lead to faster and better clearance of axonal debris. Myelin products from axonal debris are known to be inhibitory for axonal elongation and their clearance by Wallerian degeneration paves the way for restoration of the nerve conduction pathway. In addition, Büngner bands formed by proliferating Schwann cells are an important pathfinding element for growth cones of elongating axons. ${ }^{24}$ Redifferentiation of Schwann cells into the myelinating state is also important. Myelination of a higher number of axons and/or thicker myelin deposition around axons leads to a better insulation of elongated axons. Insulation also increases the rate of transmission, resulting in shorter latency, as desired with the therapy.

Besides the potential role of IKVAV sequence, mimicking of sulfated GAG-growth factor interaction is also expected to contribute to the peripheral nerve regeneration. FGF-2 secretion is known to be upregulated after PNI. FGF-2 is a heparin binding growth factor with a neurite inducing capability besides its role in Schwann cell proliferation. ${ }^{25}$ We previously showed that FGF-2 also binds to GAG-PA with high affinity. ${ }^{26}$ Better preservation of FGF-2 along with the increased local concentration on peptide nanofibers and effective presentation to cell surface receptors could also contribute to the improved functional outcome in LN-PA/GAG-PA functionalized conduit treated rats. Besides FGF-2, NGF plays a crucial role in nerve injury repair. NGF was also found to prevent cell loss, protect neurons after sciatic nerve transection ${ }^{27}$ and increase the number of myelinated axons in the regenerating nerve. ${ }^{28}$ To increase the local concentration of NGF at the injury site, NGF solution might be delivered to the injury site, but this is not feasible owing to rapid diffusion in extracellular fluids, and also sustained delivery of NGF is not favorable in terms of cost and surgical risks. Instead, induction of NGF release from Schwann cells at the injury site would be more effective. In in vitro studies, we showed that Schwann cells cultured on LN-PA/GAGPA scaffold released a significantly higher level of NGF compared with cells cultured on K-PA/E-PA scaffold and PLL coated surface. Thus, LN-PA/GAG-PA scaffold can provide a prolonged delivery of NGF and enhance the efficacy of nerve regeneration, which makes this scaffold a promising approach for PNI treatments.

In good coherence with functional analysis results and in vitro results, histological analysis also pointed out LN-PA/GAGPA biofunctionalized conduits as the most effective treatment used in this study. Axonal outgrowth with linearly ordered structure is clearly observed not only in the proximal region but also in the distal region in nerves treated with LN-PA/GAG-PA filled NGCs. Lack of Wallerian degeneration, denervation and condensed staining of $\beta$-III-tubulin along with S100 immunostaining indicated the axonal regeneration through the distal stump and repopulation by Schwann cells. We suggest that this regenerative effect is mediated by both the physical guidance offered by nanofibers and biological signals incorporated on nanofibers. Nanofiber network filling the conduit through the distal stump can potentially act as a physical pathfinding element for elongating axons from the proximal stump. Lack of reintegration at the distal stump in nerves treated with empty conduits supports this idea. 
Besides the physical guidance provided by the continuous nanofiber network, bioactive signals provided in LN-PA/GAG-PA filled conduits enhance axonal elongation. This is clearly observed in histological images in the far distal region. After the initial clearance of nerve fragments in the distal part by Wallerian degeneration, elongated nerves could reach the distal stump in sufficient numbers and form a healthy continuous path to the end target organ with the help of laminin and GAG mimetic groups presented on LN-PA/GAG-PA nanofibers. In the absence of these groups, although there were some axons that reached their destination, this was not enough to completely renervate the denervated tissue. Inability to achieve renervation in the distal region leads to muscle atrophy, which eventually leads to improper, if any, gain of function in the long term. ${ }^{29}$ Successful renervation observed in LN-PA/GAG-PA treated nerves explains the improved gain of function in these rats.

Overall, histological analysis clearly pointed out improved sciatic nerve repair when treated with LN-PA/GAG-PA biofunctionalized conduits. Axons elongated from the proximal end of the injury reached beyond the distal stump, axonal density was higher with no sign of denervation in the far distal region, good linear ordered tissue structure was constituted and Schwann cells populated newborn nerves efficiently. These histological findings explain the better functional outcome in rats treated with LN-PA/GAG-PA nanofiber functionalized conduits containing laminin derived and GAG mimetic epitopes. Physical guidance of elongating axons for pathfinding towards the distal stump also proved to be important, as can be seen from the better regeneration in K-PA/E-PA filled conduit repaired nerves than in the nerves repaired with empty conduit. However, physical guidance in the conduit lumen alone was apparently not sufficient. Though providing a better regeneration than the empty conduit, lack of biological signals in K-PA/ E-PA obviously leads to an incomplete renervation of the tissue beyond the distal injury site, which emphasizes the importance of biological signals of the scaffold for better histological and functional outcomes.

\section{Conclusion}

Guidance of regenerating axons for healthy pathfinding towards the distal stump is essential in peripheral nerve injury, especially those with full transection. Transected nerves with long gaps between the proximal and distal ends have poor regenerating ability owing to the lack of guidance, which results in a very little number of axons reaching to the distal end target organ. This results in lack of gain of function after injury and there occurs a possibility of neuroma formation by unguided growth of axons from the proximal stump. Polymeric nerve guidance conduits are used clinically to provide isolation to regenerating axons, making it easier for them to extend towards their target. However, lack of bioactive signals limits the success of these guidance tubes, resulting in worse regeneration than expected. In this study, we used peptide nanofibers mimicking the healthy ECM around neural cells to introduce bioactivity into the lumen of a clinically used nerve guidance conduit (Neurolac TW®) made of poly(DL-lactide- $\varepsilon$-caprolactone).
Conduits filled with heparan sulfate and laminin mimetic peptide nanofibers significantly improved electromyography response and promoted neuronal regeneration in a rat model of sciatic nerve defect. In addition, Schwann cells cultured on these nanofibers showed increased viability and significantly enhanced NGF release. Overall, these results suggest that extracellular matrix mimetic peptide nanofibers present a promising treatment option for peripheral nerve injuries.

\section{Acknowledgements}

We thank Z. Erdogan and M. Guler for their technical help in purification and characterization of PA nanofibers. We also thank the Research and Development Center of Gülhane Military Medical Academy for providing experimental animals. This work was funded by the Scientific and Technological Research Council of Turkey (TUBITAK) grant no 113S038. B.M. is supported by a TUBITAK-BIDEB (2211-C) Ph.D. fellowship. M.S. is supported by a TUBITAK-BIDEB (2211) Ph.D. fellowship. M.G. and Z.O. are supported by TUBITAK-BIDEB (2210-C) MSc. fellowships. M.O.G. and A.B.T. acknowledge support from the Turkish Academy of Sciences Distinguished Young Scientist Award (TUBA-GEBIP).

\section{References}

1 D. Grinsell and C. P. Keating, BioMed Res. Int., 2014, 2014, 698256.

2 A. P. Jennifer, L. Kelsey, L. M. Nelson, A. Felberg and D. P. Rice, Upper Extremity Disorders: Frequency, Impact, and Cost, Churchill Livingstone, 1997.

3 M. Siemionow, M. Bozkurt and F. Zor, Microsurgery, 2010, 30, 574-588.

4 H. Millesi, Clin. Plast. Surg., 1984, 11, 105-113.

5 R. J. Giger, E. R. Hollis 2nd and M. H. Tuszynski, Cold Spring Harbor Perspect. Biol., 2010, 2, a001867.

6 A. Li, A. Hokugo, A. Yalom, E. J. Berns, N. Stephanopoulos, M. T. McClendon, L. A. Segovia, I. Spigelman, S. I. Stupp and R. Jarrahy, Biomaterials, 2014, 35, 8780-8790.

7 F. A. Court, L. Wrabetz and M. L. Feltri, Curr. Opin. Neurobiol., 2006, 16, 501-507.

8 Z. L. Chen, W. M. Yu and S. Strickland, Annu. Rev. Neurosci., 2007, 30, 209-233.

9 Z. L. Chen and S. Strickland, J. Cell Biol., 2003, 163, 889-899. 10 M. B. Bunge, M. B. Clark, A. C. Dean, C. F. Eldridge and R. P. Bunge, Ann. N. Y. Acad. Sci., 1990, 580, 281-287.

11 T. Dvir, B. P. Timko, D. S. Kohane and R. Langer, Nat. Nanotechnol., 2011, 6, 13-22.

12 R. O. Hynes, Science, 2009, 326, 1216-1219.

13 S. Sur, M. O. Guler, M. J. Webber, E. T. Pashuck, M. Ito, S. I. Stupp and T. Launey, Biomater. Sci., 2014, 2, 903-914.

14 G. A. Silva, C. Czeisler, K. L. Niece, E. Beniash, D. A. Harrington, J. A. Kessler and S. I. Stupp, Science, 2004, 303, 1352-1355.

15 B. Mammadov, R. Mammadov, M. O. Guler and A. B. Tekinay, Acta Biomater., 2012, 8, 2077-2086. 
16 R. Kaewkhaw, A. M. Scutt and J. W. Haycock, Nat. Protoc., 2012, 7, 1996-2004.

17 J. R. Bain, S. E. Mackinnon and D. A. Hunter, Plast. Reconstr. Surg., 1989, 83, 129-138.

18 T. Nishida, K. Yasumoto, T. Otori and J. Desaki, Invest. Ophthalmol. Visual Sci., 1988, 29, 1887-1890.

19 E. O. Johnson and P. N. Soucacos, Injury, 2008, 39(3), S30S36.

20 R. V. Bellamkonda, Biomaterials, 2006, 27, 3515-3518.

21 G. C. de Ruiter, M. J. Malessy, M. J. Yaszemski, A. J. Windebank and R. J. Spinner, Neurosurg. Focus, 2009, 26, E5.

22 S. G. Turney and P. C. Bridgman, Nat. Neurosci., 2005, 8, 717719.
23 W. M. Yu, M. L. Feltri, L. Wrabetz, S. Strickland and Z. L. Chen, J. Neurosci., 2005, 25, 4463-4472.

24 V. T. Ribeiro-Resende, B. Koenig, S. Nichterwitz, S. Oberhoffner and B. Schlosshauer, Biomaterials, 2009, 30, 5251-5259.

25 C. Grothe, K. Haastert and J. Jungnickel, Brain Res. Rev., 2006, 51, 293-299.

26 R. Mammadov, B. Mammadov, M. O. Guler and A. B. Tekinay, Biomacromolecules, 2012, 13, 3311-3319.

27 D. Otto, K. Unsicker and C. Grothe, Neurosci. Lett., 1987, 83, 156-160.

28 K. M. Rich, T. D. Alexander, J. C. Pryor and J. P. Hollowell, Exp. Neurol., 1989, 105, 162-170.

29 M. G. Burnett and E. L. Zager, Neurosurg. Focus, 2004, 16, E1. 